ISSN: 2362-1303 (Paper) | eISSN: 2362-1311(Online)

JOURNAL OF ADVANCED ACADEMIC RESEARCH (JAAR) July 2016

\title{
Ethnomedical Health Care Practices among the Satar tribe of Nepal: Linking to Development Agenda
}

Author: Adhikari, L.M., PhD Scholar, Mewar University, India.

Email: lalmani.adhikari@gmail.com

Key words: Ethnomedical health care practices (EMHCP), Health seeking Behavior, 4 "A”s, Human development, traditional medicine, Satar, Nepal,

\section{Introduction}

Ethnomedical Health Care Practices (EMHCP) so called traditional medicine or indigenous health care practices are widely adopted phenomenon especially in developing countries. Inequities in availability, accessibility, acceptability and affordability of health care have increased, between as well as within populations the world over. Access to appropriate healthcare is increasingly being acknowledged as a human right through international instruments such as the United Nations Human Rights Commission, Millennium Development Goals (MDGs) and the WHO. In the recent past there has been increasing interests in integration of EMHCP relevance to public health globally. In this context, there is a critical need to mainstream EMHCP into public health care to achieve the objective of improved access to healthcare facilities.

\section{Method}

The study based on Primary data, conducted in Satar community which is sixth-most predominant ethnic group by population in Jhapa district of Nepal. Using Semi-structured tool as the data collection; cross sectional descriptive study was employed. The male household heads of Satar aged 24-49 years are selected as primary respondents. Fifty sampling units from 5 VDCs were selected using purposive sampling technique. The data are analyzed through Frequency and descriptive statistics to describe the preference of medication practices in common illnesses over 4 "A"s of health seeking behavior, attitude and satisfaction towards EMHCP comparing with modern medication.

\section{Result and Discussion}

Overall two-third (64\%) of Satar population adopts the EMHCP as majority of population has been cured through Traditional medication (50\%) followed by Faith healers $(32.1 \%)$ for the most common illnesses. The Illiterate category seek EMHCP more frequently with compared to the Literate Category which was found strongly significant $(\mathrm{P}<0.01)$. There is no significant difference between Poor and Rich category $(p>0.8)$. However, the overall frequency of EMHCP users in both category found quite high (68\%) with 
comparison to Modern medication. The analysis of 4 "As" model in health seeking practices, EMHCP users can afford the EMHCP compared to Modern medication users for seeking Modern medication which was found very significant $(\mathrm{P}<0.001)$. The availability, accessibility and Acceptability frequency for EMHCP is very high compared to the Modern medicine providing the composite score 0.938 vs. 0.740 respectively. The mean attitudinal scale of EMHCP over the modern medicine found to be 4.12 out of 5 which is very significant.

Conclusion: EMHCP phenomenon is widely prevalent in the disadvantaged and marginalized ethnic societies. People adopted different types of EMHCP according to their available choices in the common public health problems for their various health needs

\section{Introduction}

Ethnomedical Health Care Practices (EMHCP) so called traditional medicine or indigenous health care practices are widely adopted phenomenon especially in developing countries. Inequities in availability, accessibility, acceptability and affordability of health care have increased, between as well as within populations the world over. Human development is the approach of enlarging people's choices and improving human capabilities and freedoms so they can live a long and healthy life, access to education and a decent standard of living, participate in their community and the decision that affect their lives (UNDP, 2012). Thus Human development regards Health as the core phenomenon of the approach of development. Health itself has physical, mental, social and spiritual dimensions of human beings, the ethnomedical health practices are socially sanctioned and approved behavior which directly contributed in the maintenance of primary health care services in colonized and disadvantaged communities like ours seemed to be difficult as Nepal being the multicultural, multiethnic, religiously secular and ecologically diversified country with rich in fauna and flora.

In the recent past there has been a growing interest in Traditional medicine/Complementary and Alternative Medicine (TCAM) and their relevance to public health both in developed and developing countries. In this context, there is a critical need to mainstream EMHCP into public health care to achieve the objective of improved access to healthcare facilities. Access to appropriate healthcare is increasingly being acknowledged as a human right through international instruments such as the United Nations Human Rights Commission, Millennium Development Goals (MDGs) and the World Health Organization (WHO) (Unnikrishnan, 2012). Diversity, flexibility, 
easy accessibility, broad continuing acceptance in developing countries and increasing popularity in developed countries, relative low cost, low levels of technological input, relative low side effects and growing economic importance are some of the positive features of traditional medicine (WHO, 2002). However, evidence suggests that a gap between individual choices the public make in terms of integration of different medical systems and the EMHCP policy formulation and their implementation. According to WHO some of the major policy challenges include safety, efficacy, quality and rational use of traditional medicine.

The provision of health care services to people of Nepal has been found poor because of ecological terrain, low level of literacy, poor communication channels, problems with transportation, inadequate material resources, and insufficient Health care service providers among the rich, cross cultural ethnic and religious beliefs. The implementation of national health policies to provide the optimum health care services is obviously difficult. The enrollment of Female community health volunteers (FCHVs) for the delivery of primary health care services in grass-root level is one of the successful participatory frameworks of National health system. Various studies conducted at different times in the integration of ethnomedical health practices in Nepal have been found successful at the primary health care services. (Hoff, 1992) claimed that there was increased use of ORS and decreased use of purges, use of handwashing in basins, construction and use of latrines, increased referrals, and increased use of midwives for birthing.

The term Traditional Medicine (TM) refers to way of protecting and restoring health that existed before the arrival of modern allopathic medicine. As the term implies, these approaches to health belong to the traditions of each country, and have been handed down from generation to generation. TM includes diverse health practices, approaches, knowledge and belief incorporating plant, animal and/or mineral based medicines, spiritual therapies, manual techniques and exercises, applied singularly or in combination to maintain well-being as well as to treat, diagnose or prevent illness (WHO, 2002). Traditional medicine accounts for around $40 \%$ of all health care delivered in China. Up to $80 \%$ of the population in Africa uses traditional medicine to help meet their health care needs although synthetic chemical compounds have replaced many Ayurvedic plant products, the quality, safety and efficacy of natural products could be find suitable match to health care management system (Kumar and Venkatesan 2012, cited in (Sharma, Agarwal, \& Ashwini, 2003). Possibly the most famous example of a 'folk illness' is susto in Latin America Rubel (1984), cited in (Susanna Hausmann-Muela, 2003), defined an illness characterized by anxiety which does not correspond to a biomedical illness category. 'Folk illnesses' also became well-known in studies of malaria: from all over Africa, investigators reported that in the local understanding, convulsions were not 
recognised as a possible severe manifestations of malaria, but rather attributed to 'supernatural' agents, requiring treatment by a traditional healer (Susanna HausmannMuela, 2003).

(Gartoulla, 1998) has mentioned despite the health facilities provided by the government more than $50 \%$ of health problems never reach the health services. They are treated through a system of Ethnic based medical practices and pluralistic medications, which are based on home-remedies. Other methods of unconventional treatment include commercial sales of over the counter (OTC) drugs often combined with religious healing practices and culturally based treatments, which are economically beneficial to the people. M. Krishnapriya Premachandra analyzes the integration of the Ayurveda, Yoga and Naturopathy, Unani, Siddha and Homoeopathy (AYUSH) system of medicines in India ${ }^{e e}$ s health system, showing the importance of these medicines in terms of allocation of funds, institutional support, insurance schemes, growth of the manufacturing sector and reforms in the education sector. Her study shows the resurgence of traditional and complementary medicine by people both in urban and poorer rural areas of the country, indicating the community's "felt need"e for services other than those of the modern system (Swartz, 2011) and (Department of AYUSH, 2006).

(Shankar, n.d) in recent study mentioned that in Nepal more than $50 \%$ of the population uses Complementary and Alternative Medicine (CAM).In developed western countries, the use of CAM treatment modalities is widespread and increasing. In Australia, CAM has become a widely used form of healthcare and a government survey has shown that $42 \%$ of Australians report using CAM. In developing countries, more than $80 \%$ of the population still depends on CAM. In Pakistan, a developing country in South Asia, around $70-80 \%$ of the population especially in rural areas uses CAM. A study in Pokhara city and a nearby village in Nepal in the year 2001 had shown that CAM remedies constituted $32.2 \%$ of the total drugs consumed and visits to CAM practitioners accounted for $28 \%$ of the visits to health practitioners. The declaration of Alma-Ata in 1978 said that mobilization of traditional medical systems is important to make 'Health for all' a reality. CAM healers are familiar with the social and cultural background of the people, are accessible, respected and experienced. Due to various reasons allopathic doctors are reluctant to serve in rural areas ( (WHO, 1978).

Many modern medical practitioners view the increasing use of traditional medicines as a failure of allopathic medicine to satisfy the healthcare needs of society. Traditional medicine is considered to be full of spiritual and magical practices and modern medicine is seen as based on logic and verifiable by experiment. The two forms of healthcare are seen as opposites and any meaningful collaboration is excluded. However, modern medicine has often failed in conditions where behavioral, emotional or spiritual factors 
have an important causative role. In these conditions, traditional medicine has been more successful. With the increasing prevalence of psychosomatic disorders in modern society, traditional medicine will play a more important role (Shankar, n.d).

The types of Medication commonly adopted by indigenous tribes are traditional medicine, Faith healing practices and Complementary and alternative medication (CAM). The traditional medication includes Ayurvedic medicine, Homeopathic treatment, naturopathic treatment, treatment using herbal products, self medication and ritual healing practices. Faith based healing practices are also a type of traditional medicine but different category since the practices has been adopted by Satar community as their own cultural system which refers to the shamanistic practices in which the village ritual head called Majihadam provides the all cure related services. The Term Complementary and Alternative medication refers to the practice of adopting mixed medication practices in which there is at least modern medicine practices prevailed (Adhikari, 2011).

\section{Methodology}

The current research aims to explore the type of medication practices in health seeking Behavior, Attitude and satisfaction towards EMHCPs and the health outcome which supposedly address the notion of human development components viz. equity, empowerment, cooperation, Sustainability, security, and productivity among the Satar population of Nepal. Furthermore to address the integral component of Human developments the "Four As" Model for health seeking behavior in preference of EMHCP recorded as 5-point rating scale used to analyze whether the EMHCP is suitable for the tribal societies like Satar community. The four "A"s are described in given box (figure 1).

Availability: geographical distribution of health facilities, pharmaceutical products etc.

Accessibility: include transports, roads etc.

Affordability: direct, indirect and opportunity cost of health service

Acceptability: relates to socio-cultural barriers

Study population: The study has been conducted in Satar community which is sixthmost predominant ethnic group by population in Jhapa district of Nepal. The male household heads of Satar aged 24-49 years are selected as primary respondents. 
ISSN: 2362-1303 (Paper) | eISSN: 2362-1311(Online)

JOURNAL OF ADVANCED ACADEMIC RESEARCH (JAAR) July 2016

Research Design: The study has been conducted on the basis of cross sectional descriptive case study adopted to fulfill the objectives using Semi-structured questionnaires.

Sampling Design: Out of total 50 VDCs/Municipalities, Purposive sampling technique is used to select 5 VDCs and from each VDCs 10 household were selected to make total 50 sampling units. Sampling units are selected using purposive sampling techniques.. The semi-structured questionnaire; used as the tool for data collection, is designed to explore the health care seeking practices, their attitude, the use in common illnesses/sicknesses, integration into national health care system and satisfaction towards EMHCP. The analysis of prevalence of EMHCP users among the different socio-economic variables are enumerated with simple statistics.

Table 1: frequency of respondents and the preference of the type of medication

\begin{tabular}{|c|c|c|c|}
\hline $\begin{array}{c}\text { Type of Medication } \\
\text { Practices }\end{array}$ & Category & $\begin{array}{c}\text { No. of } \\
\text { Respondents }\end{array}$ & Percentage \\
\hline Western medicine & Modern Medication & 18 & $36 \%$ \\
\hline Traditional medicine & & 16 & $32 \%$ \\
\hline Faith Healers(Majihadam) & \multirow{2}{*}{ EMHCP } & 9 & $18 \%$ \\
\cline { 1 - 2 } $\begin{array}{c}\text { Complementary and } \\
\text { Alternative medication }\end{array}$ & & 7 & $14 \%$ \\
\cline { 3 - 4 } Total & & 50 & $100 \%$ \\
\hline
\end{tabular}

Source: Field Survey, 2011

The presenting common illnesses and sicknesses are varied but the two most prevalent illnesses found are Headache and Abdominal pain (Gastritis) in 76\% and 60\% (by proportion) respondents respectively. These two categories of illnesses have been cured with both modern medicine and EMHCP by different users. The frequency for both health care seeking practices has been enumerated as follows (Table3).

Table 2: Most common illnesses and the type of Medication preference for treatment

\begin{tabular}{|c|c|c|c|c|}
\hline \multirow{2}{*}{ Type of Illnesses } & \multicolumn{3}{|c|}{ Type of Medication(N) } \\
\cline { 2 - 5 } & EMHCP(N) & $\%$ & $\begin{array}{c}\text { Modern } \\
\text { Medicine(N) }\end{array}$ & $\%$ \\
\hline Headache $(\mathrm{N}=38)$ & 21 & $55.3 \%$ & 17 & $44.7 \%$ \\
\hline Abdominal Pain $(\mathrm{N}=30)$ & 19 & $63.3 \%$ & 11 & $36.7 \%$ \\
\hline Total Frequency average & 40 & $58.8 \%$ & 28 & $41.2 \%$ \\
\hline
\end{tabular}


ISSN: 2362-1303 (Paper) | eISSN: 2362-1311(Online)

\begin{tabular}{|l|l|l|l|l|}
\hline$(\mathrm{N}=68)$ & & & & \\
\hline
\end{tabular}

Source: Field Survey, 2011

The literacy status of respondents was found to be $44 \%$ including those who can read and right and had no formal schooling. The adoption of Different type of Medication practices on the basis of literacy status is described in table 3 .

Table 3: Educational Status and preference of Medication practices

\begin{tabular}{|c|c|c|c|c|}
\hline \multirow{2}{*}{ Educational Staus } & \multicolumn{2}{|c|}{ Preference of Medication practices (frequency) } & \multirow{2}{*}{$\mathrm{X}^{2}$ value } & \multirow{2}{*}{ p-value } \\
\cline { 2 - 3 } & $\mathrm{EMHCP}$ & Modern Medicine & & \\
\hline Literate $(\mathrm{N}=22)$ & 10 & 12 & \multirow{2}{*}{3.26} & $<0.001$ \\
\hline Illiterate $(\mathrm{N}=28)$ & 22 & 6 & & \\
\hline Total & 32 & 18 & \\
\hline
\end{tabular}

Source: Field Survey, 2011

\section{Table 4: Economic Status and Preference of Medication Practices}

The key occupation of Satar population was found to be labor $80 \%(n=40)$ followed by tenant farmer $16 \%(n=8)$ and the annual family income was found to be 100,000 to 200,000 NPR. Since the annual family income was found to be similar the overall economic status here presented on the basis of ownership of Land property.

Rich $=$ having the ownership of land more than 0.07 hectares

Poor= having the ownership of land less than 0.07 hectares or landless.

\begin{tabular}{|c|c|c|c|c|c|c|}
\hline \multirow[b]{2}{*}{ Economic Status } & \multicolumn{4}{|c|}{ Medication practices adopted } & \multirow{2}{*}{$\begin{array}{c}X^{2} \\
\text { value }\end{array}$} & \multirow{2}{*}{$\begin{array}{c}\mathrm{P}- \\
\text { value }\end{array}$} \\
\hline & EMHCP & $\%$ & $\begin{array}{c}\text { Modern } \\
\text { Medication }\end{array}$ & $\%$ & & \\
\hline Poor $(\mathrm{N}=34)$ & 22 & $64.7 \%$ & 12 & $33.3 \%$ & \multirow[b]{2}{*}{0.022} & \multirow[b]{2}{*}{$\begin{array}{c}\mathrm{P}>0.8 \\
7\end{array}$} \\
\hline $\operatorname{Rich}(\mathrm{N}=16)$ & 10 & 62.5 & 6 & $37.5 \%$ & & \\
\hline
\end{tabular}

Source: Field Survey, 2011

Table 5: Affordability of Health expenditure in EMHCP and modern Medicine

\begin{tabular}{|c|c|c|c|c|c|c|}
\hline $\begin{array}{c}\text { Type of medication } \\
\text { Practices }\end{array}$ & \multicolumn{4}{|c|}{ Affordability } & $\begin{array}{c}\text { correcte } \\
\mathrm{d} \mathrm{X}^{2} \\
\text { Value }\end{array}$ & p-value \\
\hline EMHCP $(\mathrm{N}=32)$ & Yes & $\%$ & No & $\%$ & \\
\hline
\end{tabular}


ISSN: 2362-1303 (Paper) | eISSN: 2362-1311(Online)

JOURNAL OF ADVANCED ACADEMIC RESEARCH (JAAR) July 2016

\begin{tabular}{|l|l|l|l|l|l|l|}
\hline Modern Medicine (N=18) & 7 & $38.9 \%$ & 11 & $61.1 \%$ & & \\
\hline
\end{tabular}

Source: Field Survey, 2011

Table: 6 Availability, Accessibility and Acceptability of services in EMHCP and modern medicine

\begin{tabular}{|c|c|c|c|c|c|c|c|c|}
\hline \multirow[b]{2}{*}{ Parameters } & \multicolumn{3}{|l|}{ EMHCP } & \multicolumn{2}{|c|}{ Modern Medicine } & \multirow[b]{2}{*}{ Mean } & \multirow[b]{2}{*}{$X^{2}$} & \multirow[b]{2}{*}{$\begin{array}{l}\text { p- } \\
\text { Value }\end{array}$} \\
\hline & $\begin{array}{l}\text { Frequenc } \\
\mathrm{y}\end{array}$ & $\begin{array}{l}\text { Percenta } \\
\text { ge }\end{array}$ & Mean & $\begin{array}{l}\text { Freq } \\
\text { uenc } \\
\mathrm{y}\end{array}$ & Percentage & & & \\
\hline $\begin{array}{l}\text { Availabilit } \\
\text { y }(\mathrm{N}=50)\end{array}$ & 45 & $90 \%$ & \multirow{4}{*}{41.75} & 39 & $78 \%$ & \multirow{4}{*}{32.25} & \multirow{4}{*}{2.80} & \multirow{4}{*}{0.42} \\
\hline $\begin{array}{l}\text { Accessibilt } \\
\mathrm{y}(\mathrm{N}=50)\end{array}$ & 48 & $96 \%$ & & 43 & $86 \%$ & & & \\
\hline $\begin{array}{l}\text { Acceptabili } \\
\text { ty }(\mathrm{N}=50)\end{array}$ & 47 & $94 \%$ & & 29 & $58 \%$ & & & \\
\hline $\begin{array}{l}\text { Affordabili } \\
\text { ty }\end{array}$ & 32 & $64 \%$ & & 18 & $36 \%$ & & & \\
\hline
\end{tabular}

Source: Field Survey, 2011

Table 7: Attitude scale of respondents towards EMHCP

The frequency of attitude level towards the EMHCP has been presented in the 5-point rating scale as shown in table 2.

\begin{tabular}{|l|c|c|c|}
\hline Rating scale & Frequency & $\begin{array}{c}\text { Total } \\
\text { Score }\end{array}$ & Mean Score \\
\hline 1 least useful & 1 & 1 & 0.02 \\
\hline 2 less useful & 5 & 10 & 0.2 \\
\hline 3 Neutral & 5 & 15 & 0.3 \\
\hline 4 Useful & 15 & 60 & 1.2 \\
\hline 5 Most useful & 24 & 120 & 2.4 \\
\hline Total & 50 & 206 & 4.12 \\
\hline
\end{tabular}

Source: Field Survey, 2011

\section{Result and Discussion}

Overall $64 \%$ of Satar population adopts the EMHCP out of which the majority of Population has been cured through Traditional medication category (50\%) followed by 
Faith healers $(32.1 \%)$ and remaining $17.9 \%$ employed Complementary and Alternative medication (CAM). The most common illnesses they have are headache and abdominal pain might have correlated with low balanced diet and anemic disorder and poor personal hygiene and sanitation. The 58.8\% respondents in average seek EMHCP pattern of treatment to cure those illnesses.44\% of illiterate respondents seek EMHCP with compared to literate respondents $(24 \%)$. The research revealed that although there is not much correlation between economically Poor and Rich category of respondents, the Poor seek EMHCP more frequently (61.7\%) than Rich category $(56.2 \%)$, the overall frequency of EMHCP by both category is found very high with comparison to Modern medication.

The analysis of 4 "As" model in health seeking practices the almost more than $87.5 \%$ of EMHCP users can afford the EMHCP compared to only $38.9 \%$ of Modern medication users for seeking Modern medication having much frequency of unaffordability $(61.1 \%)$. The availability, accessibility and Acceptibility frequency for EMHCP is very high compared to the Modern medicine providing the composite score 0.938 vs. 0.740 respectively. The relative preference of EMHCP practices over the modern medicine is analyzed through the Attitudinal rating scale (1-5), 1 being the least useful and 5, the most useful. $78 \%$ of total respondents have rated the EMHCP useful for their health care seeking practices.

\section{Conclusion}

EMHCP phenomenon is widely prevalent in the disadvantaged and marginalized ethnic societies. People adopted different types of EMHCP according to their available choices in the common public health problems for their various health needs. The human development indicators equity, EMHCP are the key phenomenon which are stuck to the community to shape their health and the having sound health is the indicator of development. The integration of EMHCP in the mainstream national health system will sustain the health care system as one of the major development achievement not only in Nepalese public health sector but also global public health. Increasing knowledge in sustainable management of health care resources basically in EMHCP should have been a policy indicator for development sector. EMHCP providers can be trained to provide medical care through the existing health network and can improve acceptance of modern primary health care practices. Community health volunteers trained in both EMHCP and modern medicine can be a devastating force for revolution of Primary health care in geographically and socially remote areas of developing countries. As the EMHCP providers can act as the active agent of changing the poor health scenario if they are empowered and cooperated to upgrade the health status of the community. While continued public legitimacy is striving and even fostering their growth, there exists a gap between public choice and national, institutional efforts for integration of EMHCP. 
Ethnicity and culture are the different attributes other than the socio-economic status which create force them to adopt the EMHCP, neither education nor economy are the liable factors for adoption of health care services but overall development which means the bottom to top approach in health care system is necessary for optimum human development. It has been revealed that the co-existence of EMHCP with other model of healthcare services is seemed to be essential. Only a single system of medicine will find it difficult to cope with the health care demands in near future. It is also obvious that traditional and cultural medical knowledge has a catalyzing effect in meeting health sector development objectives. Thus it is evident that the EMHCP is an important health care system widely approached, people centered and feasible to all strata of society which is really playing the propelling role for human growth and development from the perspectives of developmental context.

\section{References}

1. Adhikari, L. M. (2011). Health Seeking Behavior of Satar community in Jhapa district of Nepal. Unpublished MA Thesis, Tribhuvan University . Kathmandu, Nepal.

2. Department of AYUSH. (2006). International Conclave on Traditional Medicine. (pp. 1-5). New Delhi: Department of Ayurveda, Yoga \& Naturopathy, Ministry of Health and Family Welfare, New Delhi, India.

3. Gartoulla, R. P. (1998). An introduction to Medical Sociology and Medical Anthropology. Kathmandu: RECID.

4. Hoff, W. (1992). Traditional healers and community health. World Health Forum , $13(2-3), 182-187$.

5. Shankar, P. (n.d). Healing traditions in Nepal. The online journal of the American Association of integrative medicine, retrieved from www.aaimedicine.com/jaaim/sep06/Healing.pdf .

6. Sharma, L., Agarwal, G., \& Ashwini, K. (2003). Medicinal plants for skin and hair care. Indian Journal of Traditional Knowledge , 2 (1), 62-68.

7. Susanna Hausmann-Muela, S. R. (2003). Health-seeking behaviour and the health system response.Health Economics and Health Financing Program, DCPP Working Paper No. 14. 9-16. 
ISSN: 2362-1303 (Paper) | eISSN: 2362-1311(Online)

JOURNAL OF ADVANCED ACADEMIC RESEARCH (JAAR) July 2016

8. Swartz, S. (2011). TRADITIONAL MEDICINES AND HUMAN DEVELOPMENT. Universitas Forum, 2 (2).

9. UNDP. (2012). http://www.undp.org.bz/human-development/what-is-humandevelopment/. Retrieved October 10, 2012, from http://www.undp.org.bz/humandevelopment.

10. Unnikrishnan, P. (2012). Role of Traditional Medicine in Primary Health Care:An Overview of Perspectives and Challenges. Yokohama Journal of Social Sciences, 14 (6), 723-742.

11. WHO. (2002). WHO Traditional Medicine Strategy 2002-2005. Geneva: World Health Organization .

12. WHO. (1978). Declaration of Alma-Ata. International Conference on Primary Health Care. Health for All series, No. 1, www.who.int/hpr/NPH/docs/declaration_almaata.pdf. accessed on 18 Oct 2012. Geneva: World Health Organization. 